\title{
NUEVAS HIPÓTESIS SOBRE EL MANCEBO DE ARÉVALO
}

\author{
María Jesús Rubiera Mata*
}

\section{ÉPOCA Y CONDICIÓN DEL MANCEBO DE ARÉVALO}

El descubrimiento de que Baray de Reminjo era de la nación navarra, pues su nombre es la forma (Bray) navarra de Ibrahim y que seguramente fue alfaquí de Cadreita (Navarra), no de Cadrete (Aragón), que presenta en este mismo volumen Luis F. Bernabé Pons, aporta nuevos datos sobre el "Mancebo de Arévalo" con el que escribiera Ibrahim el Breve Compendio", pues nos permite precisar la cronología de la vida del Mancebo. Así, la conversación de Ibrahim de Reminjo con el fraile Esteban Martel en Cadreita debió tener lugar en 1515 cuando la expulsión de los mudéjares de Navarra; luego, Ibrahim se trasladaría a Aragón donde todavía se podía ser mudéjar y vivir en ambiente musulmán como él mismo dice:

$$
\begin{aligned}
& \text { "[...] El ver unos alimes" tan honrados me daba mucho contento el hacer } \\
& \text { asiento y reposo en Aragón [...]"2. }
\end{aligned}
$$

En Aragón se encontraría con el castellano de Arévalo y ahora podemos aventurar que fue ocho años después de la expulsión de los mudéjares de Navarra, en 1523, y no ocho años después de la obligada conversión de los mudéjares de la Corona de Aragón, cuando el navarro y el castellano escribieron el Breve Compendio ${ }^{3}$ que fue corregido "por los sabios de Aragón y los alfaquíes por cuanto el autor del libro era castellano y de gran ciencia en el adin del alislam" ${ }^{\prime 4}$.

\footnotetext{
* Universidad de Alicante.
}

1. L.P. HARVEY, «El alfaquí de Cadrete, Baray de Reminjo y el "Breve Compendio de Nuestra Ley y Sunna"», II Jornadas Internacionales de Cultura Islámica. Aragón vive su historia, (Teruel, 1988), Madrid, 1990, pp. 213-222.

2. Ibidem, p. 219

3. L.P. HARVEY, «Un manuscrito aljamiado en la Biblioteca de la Universidad de Cambridge», Al-Andalus, 21, Madrid, 1956, p. 52.

4. Manuscrito XII del catálogo Manuscritos Árabes y Aljamiados de la Biblioteca de la Junta, Madrid, 1912. 
En cambio la Tafsira se escribió más tarde según aparece también en su prólogo, donde el Mancebo describe una reunión de musulmanes en Zaragoza en la que se quejan de los quebrantos que padecen y, especialmente, de que la oración se realiza $\sin I m \bar{a} m$, sin almuédano y sin la hora canónica, y es, por tanto, "lluvia de las otonadas que la recibe la tierra con poco fruto". Y a continuación añade el de Arévalo:

"Plegue a su Divina Piedad darnos parçida contra tan fieros pertrechos que aún no llegábamos a los ocho años de nuestra conversión, cuando ya se alcanzan los destinos, unos a otros" 5 .

Los aragoneses ya tienen los problemas religiosos de los moriscos, no de los mudéjares, pues ya no tienen autoridades religiosas que les guíen desde hace siete años. Estamos, por tanto, en 1532, fecha en la que el Mancebo escribe la Tafsira antes de marcharse de peregrinación. Así, pues, podríamos suponer que la actividad como escritor en aljamiado del Mancebo se extiende sobre unos diez años, entre 1523 y 1533 aproximadamente.

Antes de esta fecha hay que situar indudablemente sus visitas a Granada y este adelantamiento temporal en su trayectoria vital corresponde con la posibilidad de su encuentro con personajes granadinos que han vivido la toma de Granada (1492) y confirma la frase de José Benegas:

“[...] si el rey de la conquista no guarda fidelidad, qué aguardamos de sus sucesores...."

Esta afirmación parece indicar que aún vive Fernando el Católico (m. 1516). Por otro lado, y según ha hecho ver Serafín de Tapia, los moriscos abulenses viajan con frecuencia a Granada en la primera década del siglo después de la obligada conversión de los mudéjares castellanos en 1502, en busca de un terreno más propicio para seguir practicando su religión. Después la emigración castellana se dirige a tierras de la Corona de Aragón, cuando el ambiente granadino se volvió mucho más difícil ${ }^{7}$. Todo hace suponer que el Mancebo siguió el mismo proceder que el resto de sus compatriotas moriscos castellanos.

Respecto a otras fechas mencionadas en los libros del Mancebo que habría que revisar, es la mencionada por Ibrahim de Reminjo, quien dice en el Breve Compendio, refiriéndose a su colaborador:

"[...] con ayuda de un escolano de buena dotrina, avisado y de largo sarhe ${ }^{*}$; era natural de Arévalo, y decía que su madre fue cristiana veinticinco años $[. . .]^{\prime \prime 8}$.

5. Ms. LXI del catálogo de la Junta, op. cit. supra.

6. L.P. HARVEY, «Yuse Benegas, un moro noble en Granada bajo los Reyes Católicos», AlAndalus, 21, 1956, p. 301.

7. Serafín de TAPIA SÁNCHEZ, La comunidad morisca de Ávila, Salamanca, 1991, pp. 310-325.

8. L.P. HARVEY, «Un manuscrito...», p. 70. 
Si situamos la redacción del libro en 1523, la conversión al cristianismo de la madre del Mancebo no puede referirse a la de los musulmanes castellanos en 1502, sino que ha de ser anterior. Luego volveremos sobre la fecha de conversión de la madre del Mancebo.

El Mancebo se nos empieza a dibujar como un hombre con unas coordenadas espacio temporales muy concretas: es criptomusulmán castellano. $Y$ ejerce un oficio muy frecuente entre los moriscos castellanos abulenses: no nos referimos al de azadonero, sino al de arriero. Se ha pensado que su oficio era el de azadonero, admitiendo literalmente sus palabras:

"[...] qué hará un miserable azadonero, que no sabe sino cortar leños en invierno, segar heno en verano $[\ldots]^{\prime \prime}$.

Pero ¿qué hace un humilde azadonero, un segador de heno, comprando cajas para transportar espadas de lujo, las espadas del Maestro Perrillo? Así nos dice el Mancebo:

"[...] Yo salí un día de lunes de Almería para subir a San Clemente adonde me aguardaba Ibrahim González de Ávila, que nos hacían dos huchas de espadas un grande maestro que le llaman el Perrillo y nos costaron una dobla cada hucha $[\ldots]^{\prime 10}$.

Así, pues, el Mancebo sale de Almería y se dirige a San Clemente (Cuenca) donde le espera un abulense, Ibrahim González, para que les hiciesen dos cajas de espadas del Maestro Perrillo. Son las espadas fabricadas por Julián del Rey, un morisco, por cierto, que llevaba ese nombre por haber sido su padrino Fernando el Católico, siendo conocido además de por el Maestro Perrillo, por el Moro de Toledo ${ }^{11}$. Sus espadas llevaban una marca de un animal que fue conocido por el "Perrillo", marca que se puede ver en una espada jineta de Boabdil que se conserva en la Biblioteca Nacional de París ${ }^{12}$. El hijo de Julián del Rey fue también espadero y su técnica continuó hasta la época de Cervantes que cita en varias ocasiones las espadas del Perrillo, diciendo que Don Quijote llevaba una simple espada y no las cortadoras del Perrillo. Eran espadas de calidad, de lujo, que le cuestan al Mancebo una dobla de oro cada una. Aunque el socio capitalista pudiera ser Ibrahim González de Ávila, el Mancebo se nos presenta implicado en un comercio de

9. L.P. HARVEY, «El mancebo de Arévalo y la tradición cultural de los moriscos», Actas del Coloquio Internacional de Literatura Aljamiada y Morisca (Oviedo,1972), Madrid, 1978, p. 31.

10. María Teresa NARVÁEZ, «Nozaita Kalderan: partera y experta en el Corán», Actas del III Simposio Internacional de Estudios Moriscos. Las prácticas musulmanas de los moriscos andaluces (1452-1605), Zaghouan (Túnez), 1989, p. 146. Hemos modernizado el texto según la ortografía del castellano actual, dejando sólo las irregularidades fonéticas y sintácticas. Naturalmente leemos Ibrahim por Baray.

11. Enrique DE LEGUINA $\times$ VIDAL, Arte Antiguo. Los maestros españoles, Sevilla, 1897, pp. 142-143.

12. J.J. Rodríguez LORENTE, "La marca del perrillo del espadero español Julián del Rey", Glaudius, 3, 1964, pp. 89-97. 
lujo, ajeno a la actividad de un humilde segador de heno. Parece un arriero o trajinante inmerso en las redes comerciales de los moriscos abulenses y que ha estudiado con detenimiento Serafín de Tapia ${ }^{13}$. Sólo con este oficio se explica el complejo itinerario del Mancebo que menciona en sus obras las siguientes poblaciones como si hubiese estado en ellas: Almagro, Almería, Astorga, Ávila, Córdoba, Gandía, Granada, Jaén, Málaga, Ocaña, Requena, Ronda, San Clemente, Segovia, Toledo, Valencia y Zaragoza.

\section{LA eSPIRITUALIDAD “CRISTIANA” DEL MANCEBO}

Si el Mancebo de Arévalo pertenece sociológicamente a su patria natal abulense, también su espiritualidad sólo puede explicarse en el contexto de la espiritualidad de su tierra y de su época. Es en este contexto donde se encuentran las claves de su obra, mucho más que en la espiritualidad musulmana, ausente en sus escritos como ya vieron Luce López-Baralt y $\mathrm{M}^{\mathrm{a}}$ Teresa Narváez ${ }^{14}$. El Mancebo de Arévalo se enmarca en la espiritualidad cristiana de su época, que él hace el esfuerzo de islamizar, combinando ambas religiones en el Breviario sunní.

La prueba inicial de la filiación del Mancebo con la espiritualidad cristiana de su época es, sin duda, el hallazgo hecho por Gregorio Fonseca de la utilización de La imitación de Cristo de Tomás de Kempis por el Mancebo en su obra Sumario de la relación y ejercicio espiritual, que el Sr. Fonseca transcribió como tesis doctoral, leída en la Universidad de Oviedo en $1987^{15}$. El Kempis, la devotio moderna, es una de las claves de esta espiritualidad hispánica de entre los dos siglos (XV-XVI), de tal forma que entre 1488 y 1500 hay cuatro ediciones incunables en castellano y dos en catalán de la Imitación de Cristo $^{16}$, con lo que el Mancebo se nos muestra inmerso en la espiritualidad cristiana de su época y posiblemente el estudio de estos incunables nos daría la clave de la versión del Kempis utilizada por el Mancebo.

Pero hay más elementos sorprendentemente coincidentes con la literatura espiritualista cristiana española del primer cuarto del siglo XVI. El Mancebo utiliza la palabra Ejercicio para titular la obra en la que cita la Imitación de Cristo y ese título es el más usado en las obras espiritualistas del primer cuarto del siglo XVI desde el Exercitatorio de García de Cisneros (Monserrat, 1500) hasta los Ejercicios Espirituales de Ignacio de Loyola, escrito

13. Serafín DE TAPIA, «Las redes comerciales de los moriscos en Castilla la Vieja: Un vehículo para sus complicidades», Studia Histórica, 11, 1993, Salamanca, pp. 231-243.

14. «Estudio sobre la espiritualidad popular en la literatura Aljamiado-Morisca del siglo XVI», Revista de Dialectología y Tradiciones Populares, 36, 1981, pp. 17-51.

15. Ma Teresa NARVÁEZ, «El Mancebo de Arévalo, lector morisco de la Celestina», Actas del IV Simposium Internacional de Estudios Moriscos, Zaghouan (Túnez), 1990, pp. 267-278.

16. Melquiades ANDRÉs, La teología española en el siglo XVI, BAC, I, Madrid, 1976, p. 387. 
fundamentalmente en 1522 en Manresa, pero que pasó un tiempo de su vida en Arévalo.

Otra prueba de la coincidencia del Mancebo con los espirituales españoles de su época es la lengua y el lenguaje utilizados. El Mancebo e Ibrahim de Reminjo utilizan según sus palabras:

"[...] los vocablos [...] serán aljamiados como se viene de una tierra a otra,y de una ribera a otra y de un lugar a otro [...]. Y por esta causa debía decir Umar Bey: he fijado mi ciencia en gente pobre $[\ldots]^{\prime 17}$.

Utilizan la lengua vulgar como hacen los espirituales españoles, como García de Cisneros, que afirma algo muy parecido:

"Compilamos así en vulgar, porque nuestra intención ha sido hacerlo para los simples devotos y no para letrados soberbios"18.

Pero no se trata de una relación superficial, ya que el Mancebo habla del concepto nuclear de la espiritualidad española del siglo XVI, de la oración mental, sólo que la llama con un pseudocultismo, tan frecuentes en el Mancebo, tal vez de exorare: sordio mental. El Mancebo como los espiritualistas cristianos recomienda la oración mental metódica:

"[...] Dice agora Umarbai: ¡Ya muslimes!, aquéllos que deseáis al-Ŷanna*, pues haced cada día un sordio mental con grande codicia de opramiento, porque es un hecho más relumbrante que he conocido y sea con devoción segura. $\mathrm{Da}$ poco o mucho, lo que sea o pueda dikar ${ }^{*}$, porque es un aviso muy documental y hase de tomar una posición dedicada, y ha de ser después de azuhar cuando la querrá dikar, hasta que dentre la hora de al-asar*, y no puede ser este sordio para ser puntual, menos de una hora, y si es menos también oirá Allah [...]"19.

Su contemporáneo, García Jiménez de Cisneros, primo del cardenal, en su Exercitatorio de la vida espiritual, ya mencionado, recomienda hacer la oración por la noche, después de completas o de madrugada después de maitines $^{20}$. Ambos no contraponen la oración mental a la vocal sino que propugnan su práctica cuando vacasen -utilizan ambos este verbo- de otras obligaciones. Dice el Mancebo:

"[...] no puede ser la recluida apta sin exercicio y no se ha de entender el exercicio por el assala" sino por lo que se ofrece en horas de vacación cuando el salih $^{*}$ toma su devoción y el dotomado se pone en contemplación con tal acordanza como es lo que representa a vislumbre de lo que leyó o de lo que entendió de las escrituras [... $]^{\prime 21}$.

17. L.P. HARVEY, «Un manuscrito...», p. 70.

18. M. ANDRES, Historia..., p. 82.

19. Sumario de la relación y ejercicio espiritual, B. N. de Madrid, Mss. Res 245, f. $10 \mathrm{v}$.

20. M. ANDRÉs, La teología..., p. 189.

21. Sumario, f. $1 \mathrm{r}$ y v. 


\section{Y García de Cisneros:}

"[...] No sin causa ordenaron los santos padres que en cierto tiempo del día y de la noche vacasen los religiosos a la oración mental [...]"22.

El propósito del Mancebo al escribir su obra es poner al alcance de todos un libro de espiritualidad en lengua vulgar, pero creando un lenguaje nuevo. Así lo dice su co-autor Ibrahim de Reminjo:

“[...] por el mejor estilo que supe colegir, por la grande ancianidad de los vocablos que defendían contra nuestro trabajo, no porque no tuvieron aquellos mejores cabidas de ciencia y prudencia que nosotros, sino que era necesario remedar aquellos vocablos y volverlos a nuestro tiempo [... $]^{\prime 23}$.

La creación de un léxico nuevo que pueda expresar la nueva espiritualidad, lenguaje que llena las obras del Mancebo de extraños neologismos, pero que también se encuentran en los textos castellanos de los espirituales. El prof. Andrés señala que Gómez García en el Carro de dos vidas (Sevilla, 1500) utiliza palabras como sublevación, evagación, soliviamiento y en el Sol de contemplativos, traducción del libro de Hugo de Balma (Toledo, 1514), se utilizan entrañal, divinal, asosiego, etc. que están en la línea de los vocablos del Mancebo $^{24}$.

Habría, por tanto, que revisar el léxico del Mancebo, no tanto desde el punto de vista filológico sino respecto a su significado espiritualista, porque el Mancebo se está inventando un nuevo lenguaje para expresar su propia experiencia espiritual, que es una de las características de los místicos españoles de la modernidad. Citamos de nuevo a Melquiades Andrés:

"Vives y nuestros místicos no se ocupan de la naturaleza del alma sino de sus vivencias inmediatas, suministradas por la experiencia cotidiana y enriquecidas con las de los otros, especialmente de un director espiritual experimentado"25.

Este camino experimental es un signo de modernidad frente al sentido medieval de cotejar continuamente a la Sagrada Escritura e igualmente el Mancebo está mencionando el Corán continuamente, pero apenas incluye aleyas coránicas, nos habla de su experiencia espiritual y se guía de las experiencias -no de los saberes- de otros que funcionan como directores espirituales $^{26}$. Los libros del Mancebo son libros de experiencia espiritual donde una y otra vez se presenta como neófito e ignorante, neófito o "mamantío", tal vez "mancebo" e incluso azadonero -la humildad de iletrado será una ca-

22. M. ANDRÉs, La teología..., p. 184.

23. L.P. HARVEY, «Un manuscrito aljamiado en la Biblioteca de la Universidad de Cambridge», Al-Andalus, 23, 1958, p. 70.

24. M. ANDRÉs, Historia..., p. 89.

25. M. ANDRÉs, La teología..., II, p. 167.

26. Ibídem, pp. 166-172. 
racterística de la espiritualidad española que llega hasta Santa Teresa- que sigue a una serie de guías espirituales, José Benegas, Ali Sarmiento, Nuzaita Calderán, la Mora de Úbeda, etc.

Es también muy característico de la época que sean mujeres las protagonistas de la espiritualidad de este periodo incluso como las guías espirituales, precisamente porque la vulgarización de las doctrinas, es decir su traducción o redacción en lengua vulgar, les permitió alcanzar unos conocimientos espirituales que antes estaban reservados a las minorías y especialmente a los varones.

Los espirituales españoles de comienzos del siglo XVI, aunque se guíen por la experiencia ajena y propia en su camino espiritual, leen libros de piedad para ayudarse. Ya hemos visto que el Mancebo usa uno de los más leídos -el Kempis- de los muchos de espiritualidad que se editaron en lengua vulgar entre 1490 y 1500 . Bajo la autoridad de autores musulmanes conocidos -Averroes, Ibn al-'Arabī- o desconocidos e imposibles de identificar desde la onomástica árabe -Umarbay, Morabay- el Mancebo introduce las ideas de la espiritualidad cristiana islamizándolas, porque la presencia del Kempis nos permite dudar de la autenticidad musulmana de las otras citas, algunas bajo las autoridades mencionadas. Lo que cabe preguntarse es si también algunos de sus guías espirituales aparecen bajo nombres ficticios, igual que sus autoridades de escritura. A mí me resulta sorprendente el nombre de la granadina Mora de Úbeda. No creo que los musulmanes granadinos, mudéjares o moriscos, se denominasen a sí mismos "moros".

\section{¿ERA EL “MANCEBO" UN CONVERSO?}

La edición del texto en la lengua de su tiempo se hace en aljamiado y no por la imprenta porque era la escritura nacional de los moriscos y la lengua utilizada no fue el castellano, lengua del Mancebo, sino la aragonesa -con navarrismos- de la literatura morisca del XVI. Pero con un problema: el Mancebo tenía una buena cultura, sabía latín aunque macarrónico, había leído o visto representar la Celestina ${ }^{27}$ y sentía el placer de crear neologismos que complican su lectura y de lo que eran conscientes tanto él como Ibrahim de Reminjo ${ }^{28}$.

A estos saberes del Mancebo hay que añadir el hebreo, tal vez también macarrónico. Harvey negó estos conocimientos ${ }^{29}$, pero con todos mis respetos al ilustre maestro, creo que sí, algo de hebreo sabía. En el Sumario incluye un extraño texto -uno más- que dice haber hallado en casa de un judío de Toledo y que era un prigrama (¿Epigrama?) que decía:

\footnotetext{
27. M.T. NARVAÉ, op.cit.

28. L.P. HaRVEY, «Un manuscrito...».

29. L.P. HARVEY, «EI Mancebo...», p. 33.
} 


\section{"Davud el Dio prosigue \\ Davud Emanue[1] surjente \\ Davud en Adunay merita \\ Davud Suma Deidad confita \\ Davud alhulla interin"}

y lo explica a continuación:

"Davud caminaba tras su Criador, porque decía que su Criador se le alejaba por sus deméritos; Davud a su Dios se levantaba tarde y mañana; Davud mediante su deidad aguardaba meritar y no mediante su rica alqafra*; Davud en su Grande Omnipotencia sostriva más que en sus trabajos; Davud puso toda alhulla, quiere decir, que se enradó en su fecho como la cal con almacén; otro, interin, quiere decir que todos los sentidos corporales cayeron en un ser efectivo" 30 .

No sabemos si será un epigrama, sí, desde luego, un galimatías. Pero hay algo muy claro, el Mancebo sabe que Adonay es el nombre de Dios y algo aún más sorprendente: utiliza el nombre de Dio usual de los judíos españoles para referirse a Dios. ¿Cómo pudo aprender algo de hebreo el Mancebo de Arévalo? Podríamos suponer que fuese estudiante de Salamanca y de ahí que conociese la Celestina, aunque precisamente a principios de siglo hubiese una crisis en la enseñanza del hebreo en dicha universidad al prohibirse a los conversos enseñar en la misma ${ }^{31}$. Tal vez fue criado de algún clérigo leído, sabedor de latines y hebreo, que al fin y al cabo, escolano, como le llama Ibrahim de Reminjo, es aragonesismo que significa discípulo, sacristán o acólito $^{32}$ y de nuevo sería una explicación más de su pseudónimo. Sin embargo resulta extraño encontrar a un mudéjar/morisco en la Universidad de Salamanca o como criado de un clérigo. Sería más creíble si el Mancebo en lugar de converso de moro, fuéselo de judío.

El Mancebo aprendió hebreo por su familiaridad con los judíos que ya eran conversos. No hay autor morisco que mencione tanto a los judíos y a los textos hebreos y además sin la menor animosidad. E incluso los enigmáticos nombres de algunas de sus autoridades espirituales, Umarbay, Murabay, tienen una terminación en - $A Y$ típica de los nombres hebreos -Hasday, Barzilay, Sabbetay, etc.- e inexplicable en árabe.

Aunque no conocemos en realidad las relaciones entre conversos y moriscos, entre los conversos de judío y de moro, esta relación resulta sorprendente. Y de ahí una hipótesis que presento con todas las precauciones: ¿No sería el Mancebo de Arévalo un converso, claramente un judío bautizado, que se convirtió al Islam? Por la misma época -comienzos del XVI- había en Roma un maestro "Alfonso de origen judío, que luego había sido moro y

\footnotetext{
30. Ff. 89 v y $90 \mathrm{r}$.

31. Carlos CARrete, El judaísmo español y la inquisición, Madrid, 1992, pp. 129-159.

32. Corominas/Pascual, D.C.E.C.H., s.v. "Escuela".
} 
que, al fin, se hizo cristiano 'pro fórmula', el cual negaba la divinidad de Cristo, la santidad del Viejo y Nuevo Testamento y la verdad de su contenido, diciendo que todo era burlería en ellos y proclamaba las excelencias del Islam o de la ley de Mahoma" y fue maestro del médico conquense Eugenio de Torralba y se le menciona en su proceso inquisitorial, según cita de Julio Caro Baroja ${ }^{33}$.

Para plantear esta hipótesis nos basamos en esta relación específica del Mancebo con los conversos, en sus rudimentarios -e insólitos- conocimientos de hebreo y en que el espiritualismo cristiano del periodo al que pertenece estuvo protagonizado por un buen número de conversos. A esto hay que añadir el dato que menciona Ibrahim de Reminjo en el Breve Compendio y que hemos mencionado más arriba: la madre del Mancebo había sido veinticinco años cristiana, años que no coinciden con la conversión de los mudéjares castellanos en 1502. Podría haber sido en 1492, cuando su madre hubo de convertirse al cristianismo, el año en que los judíos fueron obligados a exilarse o convertirse. Y la judería de Arévalo fue muy importante.

Es una hipótesis de trabajo. Pero si esta hipótesis fuese cierta el Mancebo sería el más claro exponente de las tres culturas hispánicas: judío converso, es decir, cristiano, y criptomusulmán.

\section{GLOSARIO}

Los arabismos del Ibrahim de Reminjo y el Mancebo son arabismos cultos, sacados de los textos y en muchas ocasiones no cumplen las reglas generales del funcionamiento de los arabismos integrados en las lenguas hispánicas. Incluimos un glosario de los que han aparecido en los textos empleados.

Adín. Arabismo de ad-dinn, religión.

Al-asar. Arabismo de al-'asar, oración de la tarde.

Alhulla. Arabismo de al-hulla, túnica. La frase Davud alhulla interin podría significar: se revistió interiormente.

Alimes. Arabismo de 'alim, sabio en la ciencia religiosa.

Alislam. Arabismo de al-Islām, el Islam.

Alqafra. Arabismo de al-kaffära, expiación, penitencia.

Assala. Arabismo de as-sală ${ }^{\prime \prime}$ oración". En este contexto es la oración vocal frente a la oración mental.

Azuhar. Arabismo de az-zuhr, oración del mediodía.

Dikar. Arabismo procedente de dikr en su acepción religiosa de "mencionar el nombre de Dios", rezar. El dikr es una sesión mística.

Sarhe. Arabismo de šarh, comentario, exégesis.

Salih. Arabismo de sālih, virtuoso, piadoso, devoto.

33. Julio CaRo Baroja, Vidas Mágicas e Inquisición, Madrid, 1992 ( $2^{a}$ ed.), I, p. 245. 